\title{
Quantification of LULC Changes and Urbanization Effects on Agriculture Using Historical Landsat Data in North-West Anatolia, Turkey
}

\author{
Melis Inalpulat ${ }^{1 *}$, Levent Genc ${ }^{2}$ \\ ${ }^{1}$ Çanakkale Onsekiz Mart University, Faculty of Agriculture, Department of Agricultural Structures and Irrigation, \\ Agricultural Remote Sensing Laboratory (AGRESEL), 17020, Çanakkale, Turkey \\ ${ }^{2}$ Çanakkale Onsekiz Mart University, Faculty of Architecture and Design, Department of Urban and Regional Planning, \\ Land Use and Climate Change Laboratory, 17020, Çanakkale, Turkey
}

Received: 12 June 2020

Accepted: 27 November 2020

\begin{abstract}
The Present study focused on investigation of Land Use Land Cover (LULC) changes within three basins located in North-West part of Anatolia region, Turkey. The study area consisted of six provinces with 41 districts. Visible, near-infrared and shortwave-infrared bands of Landsat imageries, acquired in production seasons of 1984, 1999, and 2014, served as main data source. The area is covered by six Landsat scenes. Supervised classification maximum likelihood algorithm was adopted whereas LULC classes were considered as forest (F), grazing-other vegetation (G-O), agriculture (A), water surface (W), and residential area-bare soil (R-B). Prior to the classification process, scenes were subset according to district boundaries, and district-level images were classified to improve the classification precision, and then mosaicked to obtain LULC $_{1984}$, LULC $_{1999}$ and LULC ${ }_{2014}$ maps. The reliabilities of maps were evaluated by accuracy assessments using 900 stratified randomized control points with minimum of 90 points per class. LULC changes were evaluated in two terms; changes within study area (WSA) (ha, \%) and changes within class area (WCA) (\%). Moreover, distributions of class areas along three basins were presented. Finally, past statuses of each class were compared, particularly, impacts of urbanization on agriculture were highlighted, and population change patterns were evaluated as main underlying reason.
\end{abstract}

Keywords: agricultural land, change detection, Landsat, LULC, urbanization

\section{Introduction}

Determination of changes in landscape properties of a certain area is an important challenge for sustainable

*e-mail: melissacan@comu.edu.tr

environmental management strategies that consider conservation and maintenance of resources [1]. The Land Use Land Cover (hereafter, LULC) type identification is declared as one of the fundamental steps in monitoring and assessment of such properties [2] due to the fact that transformation between LULC types is known to be a significant factor for global change by playing a key 
role in alternation of earth surface and its interactions with atmosphere, thus, affecting climate, habitats and biodiversity $[3,4]$. The LULC status of an area is known to change continuously especially in developing countries in response to changing needs of inhabitant. The most widespread LULC change trend on the global scale is known to be urbanization process sourced from the increase in anthropogenic activities [5] whereas direction and amounts of change depends on the cultural and social behaviors of living people together with economic and political decisions of governments, and mostly results in reduction in amounts of vital resources $[6,7]$. Historical knowledge on LULC and assessment of its change together with triggering factors, are the main necessities to understand the ongoing phenomena to develop appropriate land use planning for maintenance of environmental system functions at all scales. Since these alternations have adverse effects on the environment and human life by contributing to land patterns, hydrological networks, water quality and budget, the importance of basin scale LULC changes also comes into the frame [8,9]. In this context, remote sensing data provides reliable, labor effective and fast analysis for large area investigations due to advantages of variabilities in platform and sensor systems that offer different spatial, spectral, and temporal resolutions, wide scanning extents, and facility of charge-free data acquirement possibilities.

In the present study, the historical LULC maps of North-West Anatolia (hereafter, NWA) part of Turkey, a hotspot region, were generated using Landsat imageries acquired in production seasons of 1984, 1999 and 2014. The NWA term was restricted by the boundaries of Susurluk, North Aegean and South Marmara (hereafter, $\mathrm{S}, \mathrm{NE}$, and S) Basins. The motivation for selecting the study years was raised from the implementation dates of legacies on metropolitan municipalities (hereafter, MM) in Turkey. By the implementation of the last legacy, the distinction between urban and rural populations is abrogated through merging rural settlements of villages and towns to belonging district, making whole province a compact city that acknowledged as urban. Therefore, rigorous changes may have potential to occur, and the latest status before these changes became apparent is expected to present a repository of information. Total population of the area is continuously increasing. However, population trends of the individual settlements altered depending on the locality. Therefore, evaluating the relations in change patterns of population and urban area may help to obviate dereliction of agricultural activities resulting from rural to urban migration.

The objectives of the study were to determine land use land cover changes within (ha, \%) at NWA-level for investigation of agricultural cover loss against urban expansion, to identify which basin was faced with more severe alternations, and to assess the consistency between patterns of population and urban area in both basin and district levels. The findings of the study may present a baseline for future planning approaches and agricultural or environmental researches that will be conducted in the extent of study area.

\section{Materials and Methods}

\section{Materials}

Study Area

The NWA is covering an approximate area of 39 thousand $\mathrm{km}^{2}$ with center coordinates of $581505 \mathrm{~N}$ and 4396217 E, (Fig. 1). A total of 41 districts belonging to six provinces (Balikesir MM, Bursa MM, Canakkale, Izmir MM, Kutahya and Manisa MM) were studied.

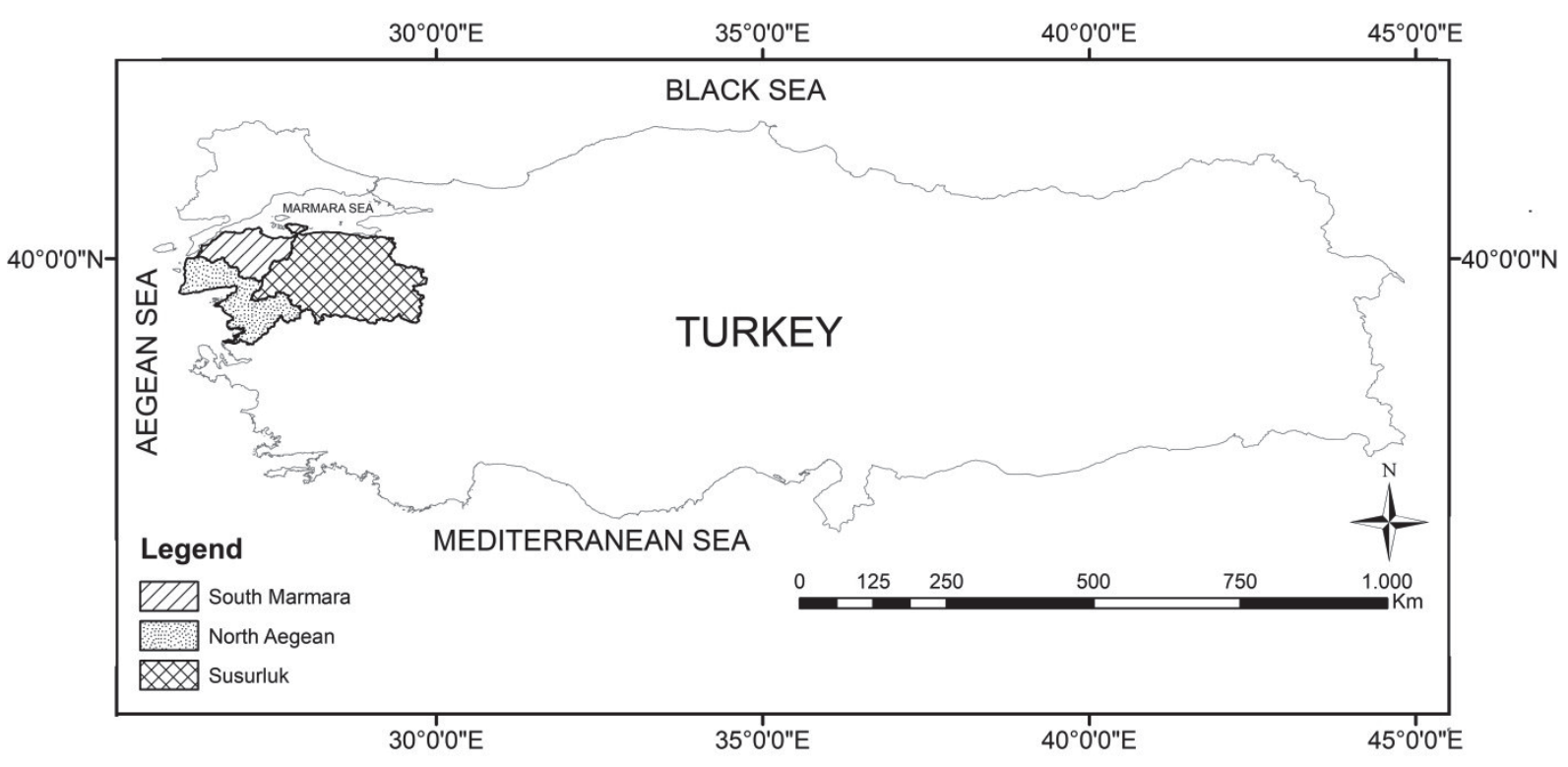

Fig. 1. Location of the study area. 
The study area is selected due to its importance in terms of industry, tourism, agriculture, and educational purposes. The population growth process mostly results in intense urban expansion leading to fast and inevitable alternations in LULC status around settlements.

\section{Remote Sensing Data}

The LULC statuses of 1984, 1999 and 2014 were determined using cloud free Landsat 5, Landsat 7, and Landsat 8 imageries acquired in productive seasons (May to October) of each year. Study area is covered by six Landsat scenes with path/row numbers of 179-181/32-33. The visible, near-infrared, and shortwave-infrared bands (6-band) of each scene were utilized. The imageries were freely downloaded from United States Geological Survey website [10].

\section{Population Data}

Population data were obtained from website of Turkish Statistical Institute (TurkSTAT) census records for each district [11]. Available records of 1985, 2000, and 2014 were used since the time difference between image and census dates were not more than months, and no extreme change was declared in the area.

\section{Methods}

\section{Generation of LULC Maps and Assessing Accuracy}

The 6-band images were classified via maximum likelihood algorithym. Five main classes were considered including forest $(\mathrm{F})$, grazing and other vegetation $(\mathrm{G}-\mathrm{O})$, agriculture $(\mathrm{A})$, water surface $(\mathrm{W})$, and residential area and bare-soil (R-B). The F class involved all types of forest tree species that found in the location, G-O class mainly ranged from grassland to natural vegetation of trees and shrubs, A class comprehend productive fields or orchards and olive groves, W class referred to natural water bodies, rivers and man-made water collection unites, and R-B class contained impervious surfaces (compactly structured settlements, industrial sites, major roads, airports and etc.) and bare soils that mostly consisted of harvested cereal areas, tilled fields or following lands. The accuracy of the classifications were determined according to [12], and 900 randomized stratified points of minimum 90 per class were controlled through Google Earth for each date.

\section{LULC Change Detection}

The class area change amounts (ha, \%) and directions (+/-) were calculated for determining overall changes within study area (WSA) (ha, \%) (Eq. 1) and within class area (WCA) (\%) (Eq. 2). The WCA, was especially required for LULC classes have comparatively smaller proportions that lead to difficulty in interpretation of changes in WSA level due to small portioned class area against large study area extents. Distributions of total class areas into basins were also investigated to comprehend the patterns of horizontal change in the phenomena for understanding which basin imposed to more drastic changes. Lastly, post classification comparison technique was applied to determine gains (or losses) from each class whereas losses from agricultural lands against residential-related class were highlighted for quantification of urbanization effects on agriculture.

$$
\begin{gathered}
W S A(\%)=\left[\left(\sum C A_{h a} / \sum S A_{h a}\right) \times 100\right]_{T 2} \\
-\left[\left(\sum C A_{h a} / \sum S A_{h a}\right) \times 100\right]_{T 1}
\end{gathered}
$$

$W C A(\%)=\left[\left(\sum C A_{h a}\right)_{T 2}-\left(\sum C A_{h a}\right)_{T 1}\right] \times 100 /\left(\sum C A_{h a}\right)_{T 1}$

...where $C A_{h a}$ is class area in hectares, $S A_{h a}$ is total study area in hectares, $T_{1}$ is the initial and $T_{2}$ is the final dates of the compared images.

\section{Evaluation of Population and Urban Area Relations}

The temporal patterns of population and urban area were plotted to assess the agreement of changes at basin level. Total R-B area (ha) and total population within each basin were considered to achieve the result. Finally, the coherencies between urban-related class (R-B) area (ha) and district populations were investigated.

\section{Results and Discussion}

\section{Results}

\section{Accuracy of Classifications and LULC Changes}

The LULC $_{1984,}$ LULC $_{1999}$, and LULC $_{2014}$ maps are represented in Fig. 2(a-c) respectively. Results of accuracy assessments were demonstrated that the overall accuracies of maps were over $\% 90.00$ for all years, and overall $\mathrm{K}$ values were calculated as 0.8779 , 0.8913, and 0.9034 for LULC $_{1984}$, LULC $_{1999}$, and LULC 2014 , respectively. There was confusion between particularly F class and G-O class especially in 1984 and continued at lower levels in 1999 and 2014. As the other noticeable error; small patched harvested crop fields misclassified as G-O in 1984 and 1999 while the confusions in 2014 were notably low.

The changes in class areas (ha, \%) of LULC classes were evaluated for NWA level for two equal time periods (Table 1). The dominant LULC type was $\mathrm{F}$ in all years, and increased progressively from $35.30 \%$ to $39.15 \%$ in 30 year period whereas WSA and WCA were slightly higher in the second term. On the contrary, area of G-O class was decreased gradually. The areas 


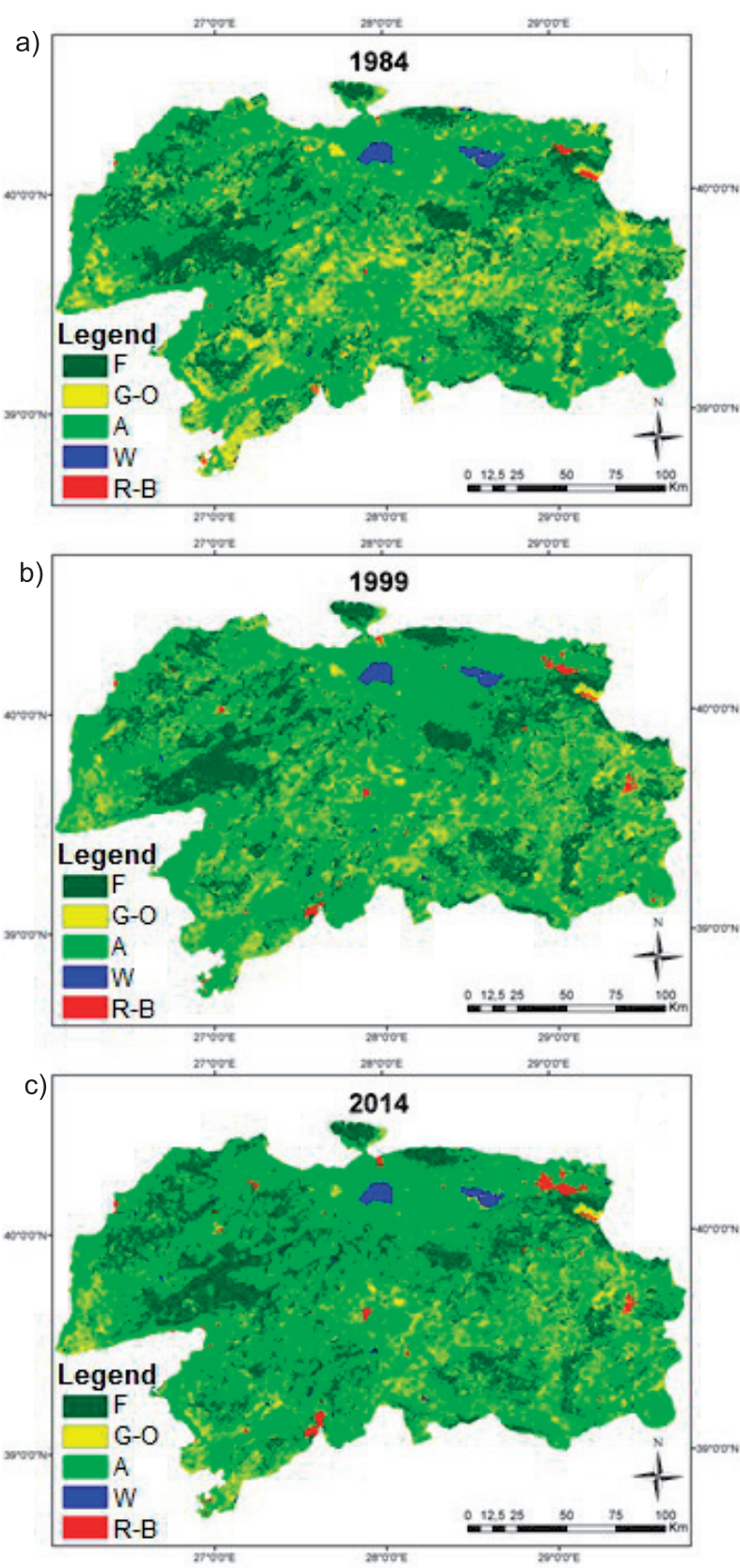

Fig. 2. LULC maps of a) 1984, b) 1999, and c) 2014.

of A class were showed an increasing tendency in both time intervals with $3.12 \%$ and $1.72 \%$. The $\mathrm{W}$ class increased by WCAs of $12.68 \%$ and $5.60 \%$, respectively. The urbanization resulted in increase in WCA by $47.60 \%$ in the first, and $25.16 \%$ in the second of R-B area, although the WSA values seemed very low in both periods $(0.11 \%$ and $0.05 \%)$.

In addition to the LULC changes in NWA, the distributions (\%) of LULC class areas between basins were investigated to answer the question of which basin have faced with more drastic changes (Fig. 3). Results showed that the majority of all classes were standing in S basin in all years, while SM basin had the minority. This situation was coherent with the magnitudes of basin areas and therefore considered as an indicator of homogeneity in class distributions among basins. Beyond the changes in F, G-O, and $\mathrm{W}$, the alternations in $\mathrm{A}$ and $\mathrm{R}-\mathrm{B}$ classes were highlighted. Proportions of A class represented a fluctuating change in NA and $\mathrm{S}$ whereas an increase occurred in first period in NA and a decrease in S basin, where urbanization sourced agricultural loss was more observable than in NA in the first time period. Meanwhile, the A portions in SM were continuously decreased due to higher increase level in NA in first period, and $\mathrm{S}$ in second period. Lastly, a similar circumstance occurred in R-B class proportions. Despite the fact that R-B class areas were increased in all basins and time intervals, the proportions in NA and SM were progressively decreased since the increase level in $\mathrm{S}$ basin was more severe than mentioned basins. The findings revealed that the most remarkable change was the progressively increased level of R-B class in $\mathrm{S}$. Therefore, $\mathrm{S}$ basin is considered to be the most sensitive area since it exposed to more drastic changes, and it was followed by NE and SM basins respectively.

\section{Gains from Each LULC Class and Highlights in $R$ - $B$ Areas}

Year-based gains of LULC classes from each other was evaluated and outlined depending on transition matrices to procure information on which classes were tent to convert to another one, (Fig 4(a, b)). The most observable conversations occurred in A and R-B classes in all years. The main source for new A areas were G-O class, whereas $14.50 \%$ of 2014 A class and $26.39 \%$ of 1999 A class were transformed from 1999 and 1984 G-O classes, respectively. Beyond the overall increase in A class area both time intervals, there were serious losses against urbanization, evidence of the situation that agricultural areas around the settlements were the main source for the new R-B areas in both years by $42.45 \%$ between 1999 and 2014, and by 32.94\% respectively.

\section{Links between Urbanization and Population}

The total population was increased approximately 1700 thousands in 30-year time period. Moreover, $68.51 \%, 19.92 \%$ and $11.56 \%$ of first year's total population are stated in S, NA and SM basins respectively, whereas the rates were alternated to $72.31 \%, 18.32 \%$ and $9.38 \%$ in 2014 with the same order. The change patterns of population and R-B class areas according to basins were correspondent (Fig. 5a). Also, the plotted situations of population and R-B area changes are seemed to have strong relations at basin level $\left(\mathrm{R}^{2}=0.9417\right)$ (Fig. 5b). Yet, the statistical analysis showed that R-B areas significantly correlated with population at 0.01 confidences in all years also at district level (41 districts). 
Table 1. Changes in class areas (ha, \%) between 1984-1999, and 1999-2014.

\begin{tabular}{|c|c|c|c|c|c|c|c|c|}
\hline \multirow{2}{*}{$\begin{array}{c}\text { Class } \\
\text { Area }\end{array}$} & \multicolumn{2}{|c|}{1984} & \multicolumn{3}{|c|}{1999} & \multicolumn{4}{c|}{ Change } \\
\cline { 2 - 10 } & ha & $\%$ & ha & $\%$ & Direction & WSA ha & WSA $\%$ & WCA $\%$ \\
\hline Forest & 1366722 & 35.30 & 1432403 & 37.00 & + & 65681 & 1.70 & 4.81 \\
\hline Grazing-Other & 1124666 & 29.05 & 915182 & 23.64 & - & 209485 & 5.41 & 18.63 \\
\hline Agriculture & 1307449 & 33.77 & 1428239 & 36.89 & + & 120790 & 3.12 & 9.24 \\
\hline Water & 33213 & 0.86 & 37424 & 0.97 & + & 4211 & 0.11 & 12.68 \\
\hline Residential-Bare & 39501 & 1.02 & 58303 & 1.51 & + & 18802 & 0.49 & 47.60 \\
\hline TOTAL & 3871551 & 100.00 & 3871551 & 100 & & & \\
\hline Class & 1999 & & 2014 & & \multicolumn{2}{|c|}{ Change } \\
\hline Area & ha & $\%$ & ha & $\%$ & Direction & WSA ha & WSA $\%$ & WCA $\%$ \\
\hline Forest & 1432403 & 37.00 & 1515822 & 39.15 & + & 83419 & 2.15 & 5.82 \\
\hline Grazing-Other & 915182 & 23.64 & 748307 & 19.33 & - & 166874 & 4.31 & 18.23 \\
\hline Agriculture & 1428239 & 36.89 & 1494932 & 38.61 & + & 66693 & 1.72 & 4.67 \\
\hline Water & 37424 & 0.97 & 39521 & 1.02 & + & 2097 & 0.05 & 5.60 \\
\hline Residential-Bare & 58303 & 1.51 & 72969 & 1.89 & + & 14667 & 0.38 & 25.16 \\
\hline TOTAL & 3871551 & 100 & 3871551 & 100 & & & \\
\hline
\end{tabular}

WSA (ha, \%): Changes within class area of whole NWA; WCA (\%): Changes within class area

\section{Discussion}

The relatively low resolution of Landsat imageries resulted in confusion in differentiation between younger $\mathrm{F}$ cover and some G-O shrubs especially in 1984 and 1999 where spectral signatures of particularly younger forest tree covers and shrubs seemed identical. The increase in maturity of younger trees leads to correct classification latter. Misclassifications between deciduous and evergreen tree types in dry season due to seasonal properties of vegetation and may be overcome by classification of imageries that acquired in winter time [13]. Also, confusion between cultivated and natural vegetated lands may source from the similarity of seasonal grasses and dry cereals [14]. Using the data acquired in the same months of each year may result in better indication of agricultural changes since the maturity of cultivated plants would be more uniform in all years. In brief, the classifications were reliable since overall accuracies,

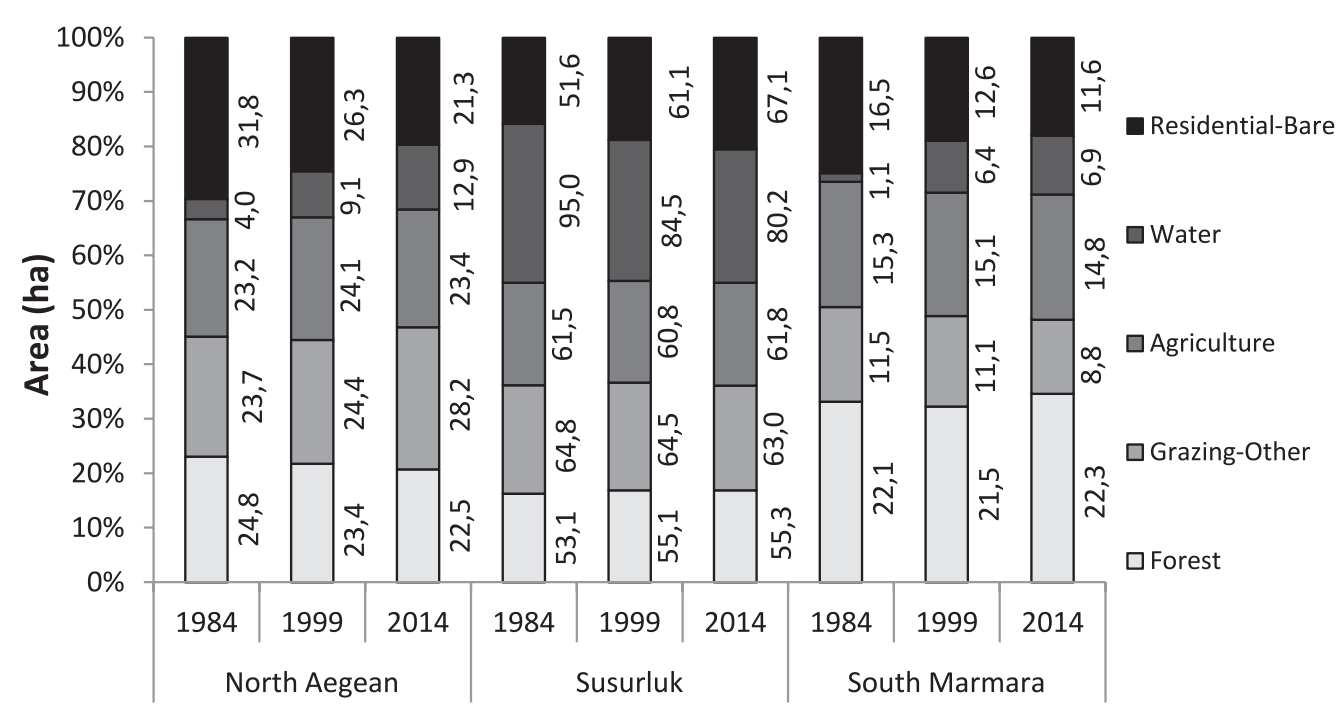

Basins \& Years

Fig. 3. Temporal distribution of LULC class areas within basins. 

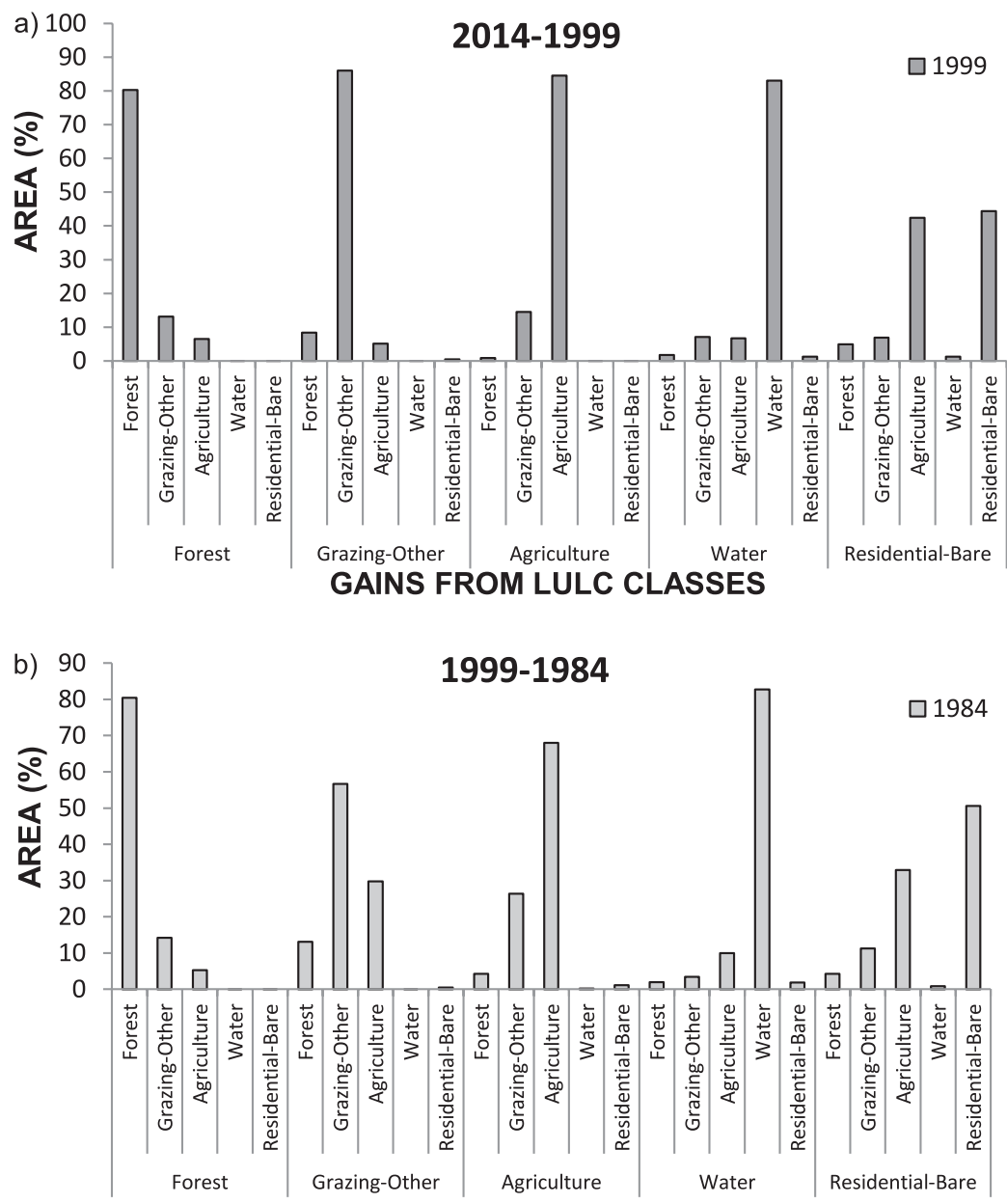

GAINS FROM LULC CLASSES

Fig. 4. Gains of each LULC type from others a) 2014 from 1999 LULC status, b) 1999 from 1984 LULC status.

overall $\mathrm{K}$ and individual $\mathrm{K}$ values were over threshold value of $0.75[15,16]$

The increasing trend of forests seemed consistent with [17]. In addition to actual changes, increase in F and decrease in G-O were quite linked to each other since there were confusions in some locations according accuracy assessments. Meanwhile, increase in A areas is probable to be aligned with the increment of $\mathrm{W}$ class with which had potential to promote irrigation practices, and lead to actual increases in areas of agricultural lands. Also, agricultural product pattern altered from unirrigated to irrigated cultivation, and increase of irrigable lands yielded in less confusion between dried above-soil materials from harvested cereal fields. The increase rate of $\mathrm{A}$ areas was lower in second period. Together with decreased rate of $\mathrm{W}$ increase, the continuing urbanization process may be one of the main responsible factors for this situation due to agricultural abandonment around urban areas. The increase in agricultural lands is a global trend since production is essential for earning efforts and human nutrition [18], whereas the experience of agricultural loss against urbanization at various rates was reported in previous studies $[19,20]$.
The $\mathrm{S}$ basin has the widest areas of $\mathrm{R}-\mathrm{B}$ and includes the major part of industrial sites and residential uses particularly in central districts of Bursa, and it was followed by Balıkesir province centre (hereafter, PC). The other PC centre Canakkale PC is located in $\mathrm{SM}$ basin. However the new urban areas Canakkale were slighter than Bursa and Balikesir PCs [21], and therefore its contributions to R-B distribution of basins were comparatively small. Although there were no PC in NE basin, the portion R-B areas were higher than SM due to crowded coastal settlements such as Edremit and Dikili districts which can be considered as hotspots for local tourism and contributing to LULC changes [22]. Depending on the above mentioned alternations, $\mathrm{S}$ basin is considered to be the most sensitive area since it exposed to more drastic changes, and it was followed by $\mathrm{NE}$ and $\mathrm{SM}$ basins respectively. On this account, monitoring and analyzing of LULC changes in the $\mathrm{S}$ basin are recommended to be conducted more precisely for planning strategies. However, urbanization seemed to have undeniable potential to compose serious threats in whole NWA level for productive lands especially located in close environment of urban growth boundaries. In such zones, with accelerating of 

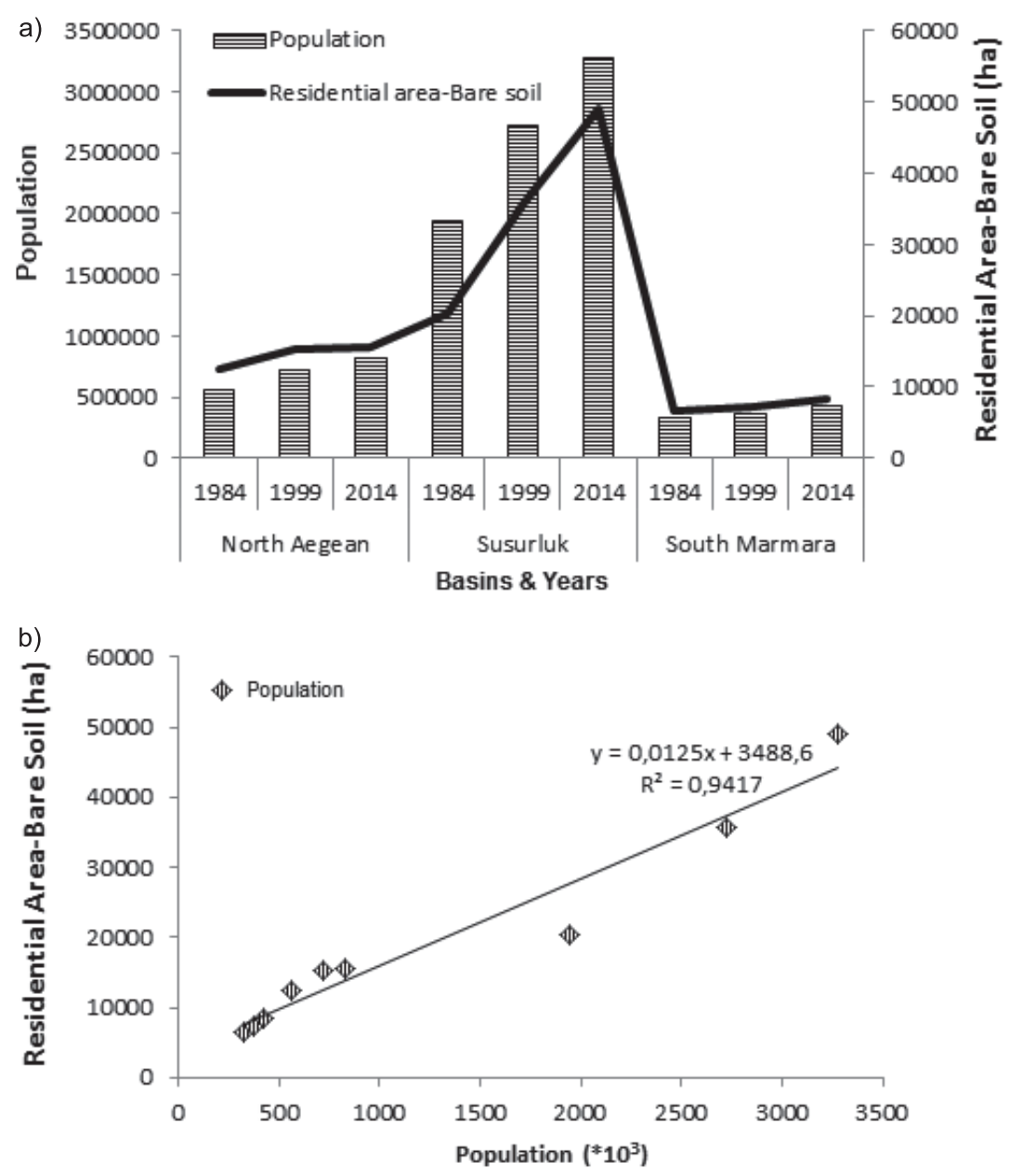

Fig. 5. Urban and changes within basins considering all years a) patterns, b) relations.

rural to urban transformation actions, preferences of people living in the urban zone usually have a tendency to leave enforcing agricultural activities, and mostly offer the productive fields on sell instead. Therefore, the process is leading to abandonment of agricultural lands continuously, and almost half of the new urban areas have gained from agriculture, in other words, agricultural loss to urbanization. The purposes of legislation in Turkey especially in recent years includes conservation of agricultural lands, however such kind of agricultural loss is still presenting a common issue particularly in living centers like cities where the impacts of growing population sensed more heavily, and the assessing relations of urban areas and population assist policies for preventing potential impairment in precise zones.

Since environmental change generally result from anthropogenic activities, population growth has a key role in shaping LULC pattern [23]. Rapid urbanization, a worldwide phenomenon, directly related with human needs and leads to outward expansion of city boundaries where the effects can be observed more clearly and drastic due to alternations in sociocultural and economic behaviors of living people depending on the disappear of functional agricultural productive lands or livestocks, threatening food security in terms of sufficiency in consequence [24]. In this case, NWA region is an important area of interest for incoming national migration which may lead to rapid changes in the environment. Therefore, understanding the relations between changing patterns of R-B and population is helpful for future environmental modeling in specified area. However, relating the population and urban area constitutes a challenge in some cases, specifically in rural areas where the population decreased and shifted to other regions, but decrease in population would not lead to decrease in R-B area as well. In fact, decrease in agricultural land per person (ALPP) can be a proof of this situation. Although the findings revealed that total areas of A class increased, the population increase was more severe, and ALPP was 0.46 ha in 1985 and decreased to 0.37 ha in 2000 and to 0.33 ha in 2014 . Some of the main reasons of decreasing population may be sourced from educational purposes of younger people or economic pressures forcing them to seek job opportunities instead of agricultural earning efforts in bigger towns or cities. The cumulative effect of this trend may eventuate in rising of agricultural product input prices, as well as other environmental and sociological issues relating to reduction in all types 
farming activities. In return, beyond any doubt, it can be said that together with population growth, urbanization is still ongoing on present day while productive lands or natural habitats are being merged by surrounding urban zones; LULC is continuously changing in response to requirements of mankind.

\section{Conclusions}

The present study was conducted in a rapidly urbanizing area of Turkey, and 30-year alternations were investigated in two equal terms. LULC classification of the area of NWA achieved good overall accuracies in all years, and noticeable amounts of actual changes have occurred in all classes. Total agricultural lands were expanded in the first period in contribution of increasing water supply possibility whereas there was a decrement in increase rate of the class in the second. Although the WSAs of urban related class (R-B) were relatively slight, the WCA seemed to be highly severe, whereas the main source for new urban areas has come mainly from agriculture. The change patterns of population and urban areas within each basin seemed identical revealed that the urbanization process proportionally triggered by population growth whereas $\mathrm{S}$ basin has experienced the most dramatic changes in terms of population, urbanization, and agricultural loss. It was recommended that overall populations can be utilized for basin or NWA level predictions related to future plans. However, R-B class area change in response to population should be analyzed more detailed at small scaled zones like districts or even villages for more precise environmental simulations, and use of imageries with higher resolutions would provide finer and more accurate results. In conclusion, the results may provide a baseline for policy and decision makers and stakeholders for future planning. The ongoing study is focused on simulating the future changes in agricultural lands in terms of topography, landscape metrics, and climate.

\section{Acknowledgements}

The paper is produced from a part of Melis Inalpulat's $\mathrm{PhD}$ Thesis.

\section{Conflict of Interest}

The authors declare no conflict of interest.

\section{References}

1. CHAMLING M., BERA B. Spatio-temporal patterns of land use/land cover change in the Bhutan-Bengal Foothill region between 1987 and 2019: Study towards geospatial applications and policy making. Earth Systems and Environment, 4, 117, 2020.

2. SILVA C.O., DELGADO R.C., TEODORO P.E., SILVA J.A. Jr., RODRIGUEZ R.A. Spatially explicit modeling of land use and land cover in the State of Rio de JaneiroBrazil. Remote Sensing Applications: Society and Environment, 18, 100303, 2020.

3. WU X., SHEN Z., LIU R., DING X. Land use/land cover dynamics in response to changes in environmental and socio-political forces in the upper reaches of the Yangtze River, China. Sensors, 8, 8104, 2008.

4. YANG H., HU D., PENG F., WANG Y. Exploring the response of net primary productivity variations to land use/ land cover change: A case study in Anhui, China. Polish Journal of Environmental Studies, 28 (5), 3971, 2019.

5. WEINZETTEL J., HERTWICH E.G., PETERS G.P., STEEN-OLSEN K., GALLI A. Affluence drives the global displacement of land use. Global Environmental Change, 23 (2), 433, 2013.

6. CHERUTO M.C., KAUTI M.K, KISANGAU P.D., KARIUKI P. Assessment of land use and land cover change using GIS and remote sensing techniques: A case study of Makueni County, Kenya. Journal of Remote Sensing and GIS, 5 (4), 175, 2016.

7. TWISA S., BUCHROITHNER M.F. Land-use and landcover (LULC) change detection in Miami river basin, Tanzania. Land, 8, 136, 2019.

8. MILLER J.D., HESS T. Urbanization impacts on storm runoff along a rural-urban gradient. Journal of Hydrology, 552, 474, 2017.

9. ADUAH M., JEWITT G., TOUCHER M. Assessing impacts of land use changes on the hydrology of a lowland rainforest catchment in Ghana, West Africa. Water, 10 (9), 2018.

10. United States Geological Survey Website (USGS). Available online: https://earthexplorer.usgs.gov (accessed on 0106 2016).

11. Turkish Statistical Institute Website (TurkStat). Available online: http://www.turkstat.gov.tr (accessed on 07.01.2016).

12. CONGALTON R.G., GREEN K. Assessing the Accuracy of Remotely Sensed Data Principles and Practices, $2^{\text {rd }}$ ed.; Lewis Publishers: Boca Raton, USA, 137, 2009.

13. XIE Z., CHEN Y., LU D., LI G., CHEN E. Classification of land cover, forest, and tree species classes with ZiYuan-3 multispectral and stereo data. Remote Sensing, 11 (2), 164, 2019.

14. YOUNIS M.T., MELIA J., GILABERT M.A., GARCIAHARO F.J., BASTIDA A.J. Lithology and vegetation cover mapping in the Guadalentin Basin as interpreted through remote sensing data. Mediterranean Desertification: A Mosaic of Processes and Responses; Geeson N.A., Brandt C.J., Thornes J.B.; John Wiley \& Sons Ltd.: The Atrium Southern Gate Chichester West Sussex, England, 277, 2002.

15. BHARATKAR P.S., PATEL R. Approach to accuracy assessment for RS image classification techniques. International Journal of Scientific \& Engineering Research, 4 (12), 79, 2013.

16. WICKHAM J., STEHMAN S.V., GASS L., DEWITZ J.A., SORENSON D.G., GRANNEMAN B.J., POSS, R.V., BAER L.A. Thematic accuracy assessment of the 2011 National Land Cover Database (NLCD). Remote Sensing of Environment, 191, 328, 2017.

17. Republic Of Turkey General Directorate Of Forestry Website [In Turkish]. Available online: https://www.ogm. gov.tr/ekutuphane/FaaliyetRaporu/Orman\%20Genel\%20 
$\mathrm{M} \% \mathrm{C} 3 \% \mathrm{BCd} \% \mathrm{C} 3 \% \mathrm{BCr} 1 \% \mathrm{C} 3 \% \mathrm{BC} \% \mathrm{C} 4 \% 9 \mathrm{~F} \% \mathrm{C} 3 \%$ BC\%202018\%20Y\%C4\%B11\%C4\%B1\%20Faaliyet\%20 Raporu.pdf (accessed on 1012 2019).

18. BESSAH E., BALA A., AGODZO S.K. OKHIMAMHE A.A., BOAKYE E.A., IBRAHIM S.U. The impact of crop farmers' decisions on future land use, land cover changes in Kintampo North Municipality of Ghana. International Journal of Climate Change Strategies and Management, 11 (1), 7, 2019.

19. SAY N., OKTEN-OZYURT S., AYSU A., YALCINKAYA N.M. Transformation of land use /land cover (lulc) under rapid urbanization in Adana, Turkey. Fresenius Environmental Bulletin, 26 (5), 3479, 2017.

20. MARTELLOZZO F., AMATO F., MURGANTE B., CLARKE K.C. Modelling the impact of urban growth on agriculture and natural land in Italy to 2030. Applied Geography, 91, 156, 2018.
21. INALPULAT M., GENC L. Land use land cover changes in response to urban sprawl within North-West Anatolia, Turkey. International Journal of Environmental, Chemical, Ecological, Geological and Geophysical Engineering, 10, 732, 2016.

22. BOAVIDA-PORTUGAL I., ROCHA J., FERREIRA C. Exploring the impacts of future tourism development on land use/cover changes. Applied Geography, 77, 82, 2016.

23. AKALU F., RAUDE J.M., SINTAYEHU E.G., KIPTALA J. Evaluation of land use and land cover change (1986-2019) using remote sensing and GIS in Dabus SubCatchment, Southwestern Ethiopia. Journal of Sustainable Research in Engineering, 5 (2), 91, 2019.

24. NJIRU E.B.K. Urban expansion and loss of agricultural land: A GIS based study of Kiambu County. International Journal of Science and Research, 8 (9), 915, 2019. 
